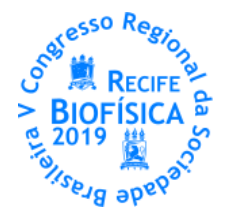

\title{
BAIXA EXIGÊNCIA DOS CONTEÚDOS DE BIOFÍSICA NO EXAME NACIONAL DE DESEMPENHO DE ESTUDANTES (ENADE) PARA ÁREA DA SAÚDE
}

\author{
André Jailson Cabral da Silva ${ }^{1}$, Tiago dos Santos Nascimento ${ }^{*, 1}$ \\ ${ }^{1}$ Faculdade do Vale do Jaguaribe - FVJ, Aracati - Ceará - Brasil \\ *andrejcs@ymail.com
}

\begin{abstract}
INTRODUÇÃO
No Brasil, o Exame Nacional de Desempenho de Estudantes (ENADE) é a avalição em larga escala do ensino superior que possui como prerrogativa fornecer dados para implementação, manutenção e reformulação de políticas educacionais para o ensino superior. 0 ENADE é um exame obrigatório para os estudantes do último ano da graduação que avalia as competências e habilidades necessárias a formação geral e científico-profissional. Em Ciências Biológicas e da Saúde (CBS), os avanços na Biofísica (BioFís) têm contribuído nas últimas décadas para o desenvolvimento da biotecnologia, medicina, dentre outros e, consequentemente, implicando em alterações na economia e política. Assim, o objetivo deste trabalho foi avaliar a relevância que o ENADE tem dado aos assuntos de Biofís.
\end{abstract}

\section{MATERIAIS E MÉTODOS}

Trata-se de um trabalho de natureza documental com análises qualitativas e quantitativas. A prospecção dos dados foi realizada em provas que compuseram os exames periódicos do ENADE em CBS, de acordo com os cursos em questão, cadernos de provas dos cursos em: Biologia/Ciências Biológicas e Física, nas modalidades Licenciatura e Bacharelado (2005, 2008, 2011, 2014 e 2017); Biomedicina (2010, 2013 e 2016) e Enfermagem, Farmácia, Fisioterapia, Medicina, Nutrição e Odontologia, todos no mesmo período de aplicação (2004, 2007, 2010, 2013 e 2016). Foram definidos como Parâmetros de Análise para as questões: leitura exploratória, identificação dos conteúdos de Biofís, e posterior, determinação da frequência relativa e interpretação dos dados, bem como, a relevância histórica no período: eventos históricocientíficos ligados à subárea de BioFís.

\section{RESULTADOS E DISCUSSÃO}

Com base nas análises das questões de todas as provas do ENADE em CBS (Biologia/Ciências Biológicas, Biomedicina, Enfermagem, Farmácia, Fisioterapia, Medicina e Nutrição) para os períodos (2004 a 2017), e, correlacionados com os conteúdos aplicados em Biofís, foi possível inferir a frequência de questões da área no ENADE. Para o curso de Nutrição, verificou-se que não foram abordadas questões relevantes à Biofís, ou seja, em todos os anos de aplicação das provas não havia citação de conteúdos nas questões objetivas e discursivas. A segunda menor frequência de questões sobre o tema ocorreu no curso de Biomedicina e Odontologia, que fizeram referência em 2010 e 2007, com uma questão objetiva cada, sobre o tema radiações ionizantes e permeabilidade vascular, respectivamente. As três questões objetivas abordadas nas provas de Medicina (2007, 2010 e 2013) foram relacionadas a assuntos complementares para leitura e entendimento de ECG's (eletrocardiogramas). Em farmácia, três questões, um item de uma discursiva e uma questão objetiva em 2004 e uma objetiva em 2013 trouxeram conteúdos sobre pressões parciais de oxigênio e calibres de artérias e veias, permeabilidade da membrana e canais de cálcio e fenômenos de transporte de fármacos transmembrana, respectivamente. As questões objetivas em 2010 (três) e 2016 (uma) da prova de Enfermagem abordavam temas sobre a mecânica da respiração, patologia e desajustes na informação nos impulsos neuronais, radiações (X e laser) e pressões parciais $\mathrm{e}$ mecânica da respiração. Com uma média de 3,2 questões objetivas por avalição, figurando em todos os anos de aplicação, Fisioterapia foi a segunda maior contagem de questões de todos os cursos avaliados, diversificando sobre os temas mecânica do movimento musculoesquelético, mecânica da respiração e pressões parciais, radiações a laser e bioeletricidade, biomotricidade, ondas eletromagnéticas, eletromiografia, estimulação neuronal, além de permeabilidade da membrana e canais de cálcio. A relevância maior em BioFís foi dada no curso de Biologia/Ciências Biológicas, conforme esperado, devido conhecimento desse ramo da Ciência compor uma das vertentes da área em BioFís. O curso de Biologia/Ciências Biológicas abrange na prova do ENADE as modalidades Licenciatura e Bacharelado, por isso é necessária uma leitura mais pormenorizada das provas. Em ambas as modalidades, as análises das questões mostraram que não houve referência sobre o assunto Biofís nas questões discursivas em nenhum ano de aplicação (2005, 2008, 2011, 2014 e 2017), sendo abordado, portanto, somente nas questões objetivas. As variabilidades de conteúdos presentes nas provas convergem para os citados nas provas de Fisioterapia, adicionando ainda fenômenos de transporte, tipos de transporte e gradientes de concentração de biomoléculas em membrana. Em contrapartida, o curso de Física fez menção sobre fenômenos óticos da visão em uma questão em 2005, primeiro ano de aplicação. Desse modo, as questões analisadas mostram que assuntos relacionados à Biofís estiveram presentes nas provas do ENADE para os cursos em avaliados, exceção feita ao curso de Nutrição.

\section{CONCLUSÕES}

Sendo BioFís a conjunção de duas grandes áreas das ciências (Física e Biologia) e pela importância interdisciplinar que possui nos conteúdos basais para os cursos das CBS, a frequência e relevância nas avaliações do ENADE têm sido pouco expressivas, quando comparado aos temas citologia, fisiologia, histologia e ecologia. BioFís é uma fração muito pequena das questões totais das provas. Assim, é possível concluir que as avaliações das grandes áreas da saúde (Biologia/Ciências Biológicas, Biomedicina, Enfermagem, Farmácia, Fisioterapia, Medicina e Nutrição) conferiram menor importância, percentualmente, a BioFís, apesar desses assuntos 
estarem entre os principais propulsores da pesquisa em CB e Saúde na atualidade.

\section{REFERÊNCIAS}

CORSO, G. The biophysical class contents and the physics. Revista Brasileira de Ensino de Física, Florianópolis, v. 31, n. 2, p. 2703-4, 2009.

BRASIL, Ministério da Educação, Diretrizes Curriculares Nacionais para os Cursos de Bacharelado e Licenciatura em Biologia. Brasília: MEC/INEP, 2002.

BRASIL, Ministério da Educação, Portaria n॰ 472 de 6 de junho de 2017 (DOU, 8 de junho de 2017, Seção 1, p. 26, 2017). Brasília: MEC/INEP, 2017.

BRASIL, Ministério da Educação, Portaria n॰ 472 de 6 de junho de 2017 (DOU, 8 de junho de 2017, Seção 1, p. 27, 2017). Brasília: MEC/INEP, 2017.

BRASIL, Ministério da Educação, Manual do ENADE 2017. Brasília: MEC/INEP, 2017.

BRASIL, Ministério da Educação, Provas e Gabaritos do ENADE 2017. Brasília: MEC/INEP, 2017. 